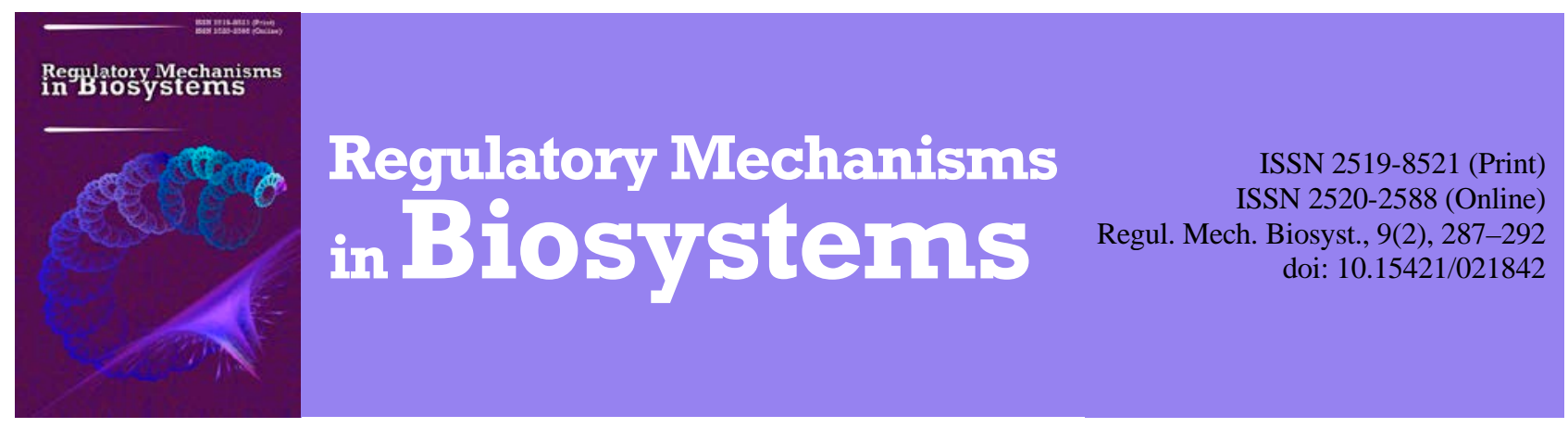

\title{
Glutathione s-transferase as a marker of oxidative stress in human ejaculated spermatozoa from patients with pathospermia
}

\author{
M. Z. Vorobets, R. V. Fafula, A. S. Besedina, O. K. Onufrovych, D. Z. Vorobets \\ Danylo Halytsky Lviv National Medical University, Lviv, Ukraine
}

Article info

Received 16.03.2018

Received in revised form 14.04.2018

Accepted 18.04.2018

Danylo Halytsky Lviv National Medical University, Pekarska st. 69,

Lviv, 79010, Ukraine.

Tel.: +38-032-275-49-66.

E-mail: roman_fafula@ukr.net

\begin{abstract}
Vorobets, M. Z., Fafula, R. V., Besedina, A. S., Onufrovych, O. K., \& Vorobets, D. Z. (2018). Glutathione s-transferase as a marker of oxidative stress in human ejaculated spermatozoa from patients with pathospermia. Regulatory Mechanisms in Biosystems, 9(2), 287-292. doi:10.15421/021842
\end{abstract}

It is believed that the most common causes of male infertility are impairment of spermatogenesis and sperm functions. Glutathione S-transferases (EC 2.5.1.18) play an important role in sperm physiology, specifically in antioxidant protection against oxidative damage. The catalase decomposition of lipid hydro-peroxides forms as a result of oxidative stress. We used a model of superoxide anion-generating system $\mathrm{Fe}^{3+}$ /ascorbate or $\mathrm{H}_{2} \mathrm{O}_{2}$-induced stress to study the activity of glutathione s transferase in human ejaculated spermatozoa from patients with pathospermia and products of lipid peroxidation (TBARS) as a marker of oxidative stress. In the present study, dose dependent increase in the level of lipid peroxidation was observed for treatment with $\mathrm{Fe}^{3+}$ /ascorbate or $\mathrm{H}_{2} \mathrm{O}_{2}$. The TBARS level was higher for sperm cells incubated with superoxide anion-generating system $\mathrm{Fe}^{3+}$ /ascorbate than for $\mathrm{H}_{2} \mathrm{O}_{2}$. GSTs activity increased in spermatozoa treated with increasing concentration of superoxide anion-generating system $\mathrm{Fe}^{3+} / \mathrm{ascorbate}^{3}$ and $\mathrm{H}_{2} \mathrm{O}$. We found that both $\mathrm{Fe}^{3+}$ /ascorbate and $\mathrm{H}_{2} \mathrm{O}_{2}$ displayed similar inhibitory effects on sperm GSTs activity, however $\mathrm{H}_{2} \mathrm{O}_{2}$ at low concentrations activated enzyme activity only in normozoospermic samples, which can be

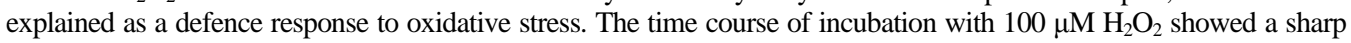
decrease in the enzyme activity during the first $5 \mathrm{~min}$ of incubation for both normozoospermic and pathozoospermic men. Preincubation of spermatozoa with GSH completely prevented the ROS-induced inhibition on GSTs only in normozoospermic samples. On the other hand, in pathospermic samples protectory effect of GSH was observed only against non-radical $\left(\mathrm{H}_{2} \mathrm{O}\right)$ radical, but not against radical (superoxide anion-generating system $\mathrm{Fe}^{3+}$ /ascorbate) species. The results of our study showed higher oxygen-free radical production, evidenced by increased TBARS level in spermatozoa obtained from infertile men than normozoospermic men. The inhibitory effect of the radical (superoxide anion-generating system $\mathrm{Fe}^{3+}$ /ascorbate) species on sperm GSTs activity and products of lipid peroxidation in sperm cells of fertile and infertile men were more expressed compared to non-radical $\left(\mathrm{H}_{2} \mathrm{O}\right)$ species. Our results indicate that estimation of sperm GSTs enzyme assays can be used as a bioindicator for impaired male fertility. The obtained results argue for a biological role of sperm GSTs in susceptibility of spermatozoa to oxidative damage and maintaining sperm antioxidant status.

Keywords: glutathione S-transferase activity; lipid peroxidation; antioxidant protection; sperm cells; pathospermia; male infertility

\section{Introduction}

Infertility is one of the most serious medical and sociodemographic problems worldwide. Approximately $30-40 \%$ of infertility cases are caused by male factors (Buzadzic et al., 2015; Esteves et al., 2015). Dramatic increase in male infertility over the last decades has been observed. Male infertility is a heterogeneous disorder which is associated with different genetic and environmental factors contributing to impaired spermatogenesis. The pathophysiology of male infertility is related to the cascade of molecular and biochemical processes which are reflected in abnormal semen parameters, for example sperm concentration, motility, morphology etc. (Hesham et al., 2008). Oxidative stress-induced sperm damage is considered as a significant contributing factor in $30-80 \%$ of all cases of male infertility (Esteves et al., 2011). It is well recognized that oxidative stress is induced by high levels of reactive oxygen species (ROS). Physiological levels of ROS are required for sperm hyperactivation, capacitation, acrosome reaction etc., however excessive levels of ROS can negatively affect functions of sperm cells. ROS can be produced by human spermatozoa. The main sources of endogenous ROS in semen are both abnormal spermatozoa and leukocytes (Sakkas et al., 2003). ROS include radical $\left(\mathrm{O}_{2}^{-{ }^{-}}\right.$and $\mathrm{HO}^{-}$) and nonradical species $\left(\mathrm{H}_{2} \mathrm{O}_{2}\right)$, with quite different stabilities and reactivities (Halliwell, 2007). These properties will depend on whether they are generated in a soluble or membrane-associated cell fraction and their targets for oxidation and mechanisms may be different (Halliwell et al., 2007; Letelier et al., 2010).

Since spermatozoa have to pass through different reproductive tract fluids in order to reach the oocyte, the exposure to ROS is high because of the presence of immune cells in the reproductive tract (Ball et al., 2005). In comparison to somatic cells, the ejaculated human sperm cells, as aerobic cells are highly sensitive to high levels of ROS or ROS-generated products since they are rich in unsaturated fatty acids on their plasma membrane (Storey, 2008; Aitken et al., 2012). To counteract the damaging effect of ROS, sperm cells have extensive antioxidant defence mechanisms. One of the defence systems against the oxidative stress in spermatozoa is the glutathione S-transferases (GSTs; EC 2.5.1.18) which detoxify electrophilic com- 
pounds. GSTs are the intensely investigated conjugation enzymes. Enzymes are multifunctional proteins ubiquitously expressed in most living organisms which catalyze glutathione (GSH, a tripeptide $\gamma$-Glu-Cys-Gly) conjugation with different toxic substrates provided with an electrophilic center (Hayes et al., 2005; Sahoo, 2011). GSTs play an important role not only in detoxifying electrophilic xenobiotics, but also in inactivation of secondary metabolites produced as a result of oxidative stress (Nissar et al., 2017). Since GSTs plays a critical role in defence mechanisms against oxidative stress in all life forms, GSTs activity also has been widely used as a biomarker to detect stress (Farombi et al., 2007). There is evidence that genetic variation in the glutathione S-transferase influences individual susceptibility to disease associated with oxidative stress (Onaran et al., 2001).

We used a model of superoxide anion-generating system $\mathrm{Fe}^{3+}$ /ascorbate or $\mathrm{H}_{2} \mathrm{O}_{2}$-induced stress to study the activity of glutathione Stransferase in human ejaculated spermatozoa from patients with pathospermia and products of lipid peroxidation as a marker of oxidative stress.

\section{Materials and methods}

Patients. 32 infertile men with pathospermia (oligozoospermia, asthenozoospermia, oligoasthenozoospermia) were involved in this study. Exclusion criteria: azoospermia, genital infection, subjects with infertility lasting over 10 years, chronic illness and serious systemic diseases, smokers and alcoholic men (because of their well-known high seminal ROS levels and decreased antioxidant activity which may affect GSTs). Subjects currently on any medication or antioxidant supplementation were not included in the study. Control group -10 healthy men with proven fertility (married for 3-10 years and have healthy 1-3 children) and normozoospermia. Semen samples were obtained by masturbation following $3-5$ days' abstinence from sexual activity. Samples were collected into sterile containers. After liquefaction (at $37{ }^{\circ} \mathrm{C}$ with $5 \% \mathrm{CO}_{2}$ in air), semen samples were examined for spermogram parameters (volume, $\mathrm{pH}$, sperm concentration, morphology and motility according to World Health Organization guidelines, 2010).

Ethical approval. All the men involved read patient information leaflets and gave informed consent to participate in the study. Terms of sample selection meet the requirements of the principles of Convention of Europe Council on Hhuman Rights, the Helsinki Declaration on Protection of Human Rights and Biomedicine and the laws of Ukraine. Approval for study was taken from the ethics committee of Danylo Halytsky Lviv National Medical University (Ethical Committee Approval, protocol No 6 from March 29, 2017).

Cell preparation. Spermatozoa were washed from semen plasma by 3 times centrifugation in media ( $\mathrm{pH} 7.4)$ which contained (mM): $120 \mathrm{NaCl}, 30 \mathrm{KCl}, 30$ Hepes (3,000 g for $10 \mathrm{~min}$ ). The total protein content in the samples was determined by Lowry method using a kit to determine its concentration (Simko Ltd.). Determination of lipid peroxidation products and GSTs enzyme activity were carried out on permeabilized spermatozoa. The detergent saponin was added to sperm suspension for permeabilization of sperm membranes (final concentration 0.5\%) (Vorobets et al., 2008).

The aliquots were subjected to exogenous ROS stimulation with superoxide anion-generating system $\mathrm{Fe}^{3+}$ /ascorbate or $\mathrm{H}_{2} \mathrm{O}_{2}\left(37^{\circ} \mathrm{C}\right.$, $\left.5 \% \mathrm{CO}_{2}\right)$ at different concentrations $(50,100$ and $500 \mu \mathrm{M})$ (if nothing else is indicated). Sperm samples without exogenous ROS served as control in the study. Also, when indicated, reduced glutathione (5.0 mM GSH) was present during the ROS-treatment.

GSTs Enzyme Assay. The activity of glutathione S-transferase was determined spectrophotometrically using enzyme-catalysed condensation of glutathione with 1-chloro-2,4-dinitrobenzene as an electrophilic substrate. The product formed (2,4-dinitrophenyl-glutathione) absorbs light at $340 \mathrm{~nm}$ with an extinction coefficient of $9.6 \mathrm{mM} / \mathrm{cm}$. The reaction mixture in a volume of $3 \mathrm{~mL}$ contained $2.5 \mathrm{~mL}$ of $0.1 \mathrm{M}$ potassium phosphate buffer (pH 6.5), $0.2 \mathrm{~mL}$ of $15 \mathrm{mM}$ CDNB and $0.3 \mathrm{~mL}$ of $30 \mathrm{mM} \mathrm{GSH}$, as enzyme source. The reaction was initiated by glutathione.
Lipid peroxidation. Peroxidative damage was estimated spectrophotometrically by the assay of thiobarbituric acid reactive substances (TBARS) and expressed in terms of nmole of malondoialdehyde (MDA) formed per mg protein (Timirbulatov et al., 1981).

Statistical analysis. The results are presented as the mean \pm standard error $(\mathrm{M} \pm \mathrm{SE}$ ). Analysis of variance (ANOVA) was used to compare the difference in the means between studied groups. Differences were considered statistically significant at $\mathrm{P}<0.05$ for all analyses.

\section{Results}

The present study analyzes the effect of the radical (superoxide anion-generating system $\mathrm{Fe}^{3+}$ /ascorbate) and non-radical $\left(\mathrm{H}_{2} \mathrm{O}\right)$ species on sperm GSTs activities and lipid peroxidation products in sperm cells of fertile and infertile men.

Lipid peroxidation products in response to oxidative stress. Dose dependent increase in the level of lipid peroxidation was observed on treatment with $\mathrm{Fe}^{3+}$ /ascorbate or $\mathrm{H}_{2} \mathrm{O}_{2}$ (Fig. 1). For normozoospermic samples, the increase in the TBARS level was significant for the dose of ROS higher than $100 \mu \mathrm{M}$ used in the experiment compared to untreated sperm cells. However, for pathospermic samples the increase in the TBARS level was significant for all doses of ROS. As can be seen from Figure 1, the TBARS level was higher for sperm cells incubated with superoxide anion-generating system $\mathrm{Fe}^{3+}$ /ascorbate than for $\mathrm{H}_{2} \mathrm{O}_{2}$.

To establish whether products of lipid peroxidation did affect sperm, normozoospermic and pathospermic sperm samples were incubated with exogenious $\mathrm{Fe}^{3+}$ /ascorbate or $\mathrm{H}_{2} \mathrm{O}_{2}$ and GSTs activity of the spermatozoa was recorded (Fig. 2). This experiment shows that the byproducts of lipid peroxidation generated by $\mathrm{Fe}^{3+}$ /ascorbate or $\mathrm{H}_{2} \mathrm{O}_{2}$ treatment caused decreases in sperm GSTs activity in dose dependent manner. However, in normozoospermic samples low concentrations of $\mathrm{H}_{2} \mathrm{O}_{2}(50 \mu \mathrm{M})$ induced activation of sperm GSTs activity to $144 \%(\mathrm{P}<0.01)$ in comparison with untreated cells. For similar concentrations of $\mathrm{Fe}^{3+} /$ ascorbate a significant decrease in GSTs activity was observed, particularly in pathospermic samples. The residual GSTs activities remained in both normo- and pathospermic samples. Similar results were obtained for sperm cells of patients with oligoasthenozoospermia (data not shown).

Also, sperm cells were incubated with $100 \mu \mathrm{M}$ anion-generating system $\mathrm{Fe}^{3+}$ /ascorbate or $\mathrm{H}_{2} \mathrm{O}_{2}$ at different times and then GSTs activity was determined (Fig. 3). The time course of incubation with $100 \mu \mathrm{M} \mathrm{H}_{2} \mathrm{O}_{2}$ showed a sharp decrease in the enzyme activity during the first 5 min of incubation for both normozoospermic and pathozoospermic men. The residual GSTs activities remained in normo- and pathospermic samples after $15 \mathrm{~min}$ of incubation with both aniongenerating system $\mathrm{Fe}^{3+}$ /ascorbate and $\mathrm{H}_{2} \mathrm{O}_{2}$.

It is known that thiol groups in GSTs enzymes can be protected by pre incubation with its cofactor GSH because the redox-reactive cysteine residues may be located in the region for GSH binding (Cheng et al., 2001). In order to evaluate this protective effect, we investigated whether pre-incubation (20 min) of the spermatozoa with the cofactor GSH affects GSTs activity under oxidative stress. As can be seen from Figure 4, the pre-incubation of spermatozoa with GSH completely prevented the ROS-induced inhibition on GSTs only in normozoospermic samples. On the other hand, in pathospermic samples, the protective effect of GSH was observed only against nonradical $\left(\mathrm{H}_{2} \mathrm{O}\right)$ radical, but not against radical (superoxide aniongenerating system $\mathrm{Fe}^{3+} /$ ascorbate) species.

\section{Discussion}

It is believed that the most common causes of male infertility are impairment of spermatogenesis and sperm functions. The factors contributing to abnormal sperm functions leading to infertility are not fully understood (Said et al., 2005). Oxidative stress in spermatozoa is one of the factors related to male infertility (Joffe, 2010; Garrido et al., 2004). The purpose of the present study was to evaluate the effects of the radical (superoxide anion-generating system $\mathrm{Fe}^{3+} /$ ascorbate) and 
non-radical $\left(\mathrm{H}_{2} \mathrm{O}\right)$ species on TBARS levels and GSTs activity and in spermatozoa of fertile and infertile men. Previously, the increased TBARS level and decreased GSTs activity in spermatozoa obtained from infertile men were reported by our laboratory. We have shown that TBARS level in spermatozoa of men with oligozoospermia, astenozoospermia, oligoastenozoospermia and leucocytospermia was sig-

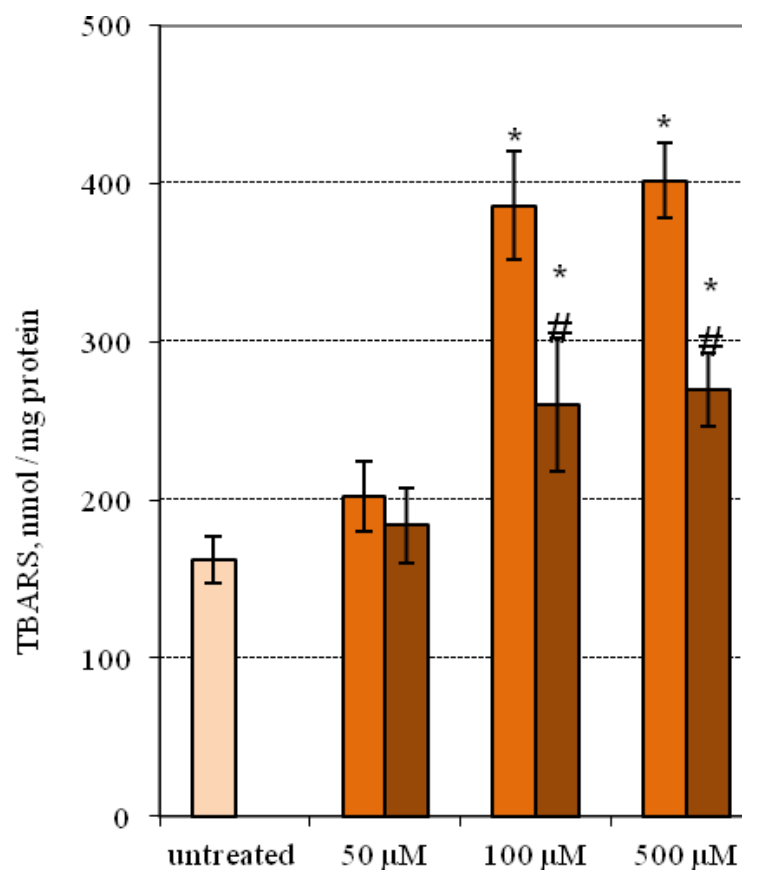

nificantly higher than in normozoospermic samples (Fafula et al., 2017). As a result of the correlation analysis we found an inverse correlation between TBARS content in spermatozoa in infertile men and the number of sperm cells in the ejaculate, their motility, which indicates direct pathogenetic link between the level of lipid peroxidation and decrease in fertility potential (Fafula et al., 2017).

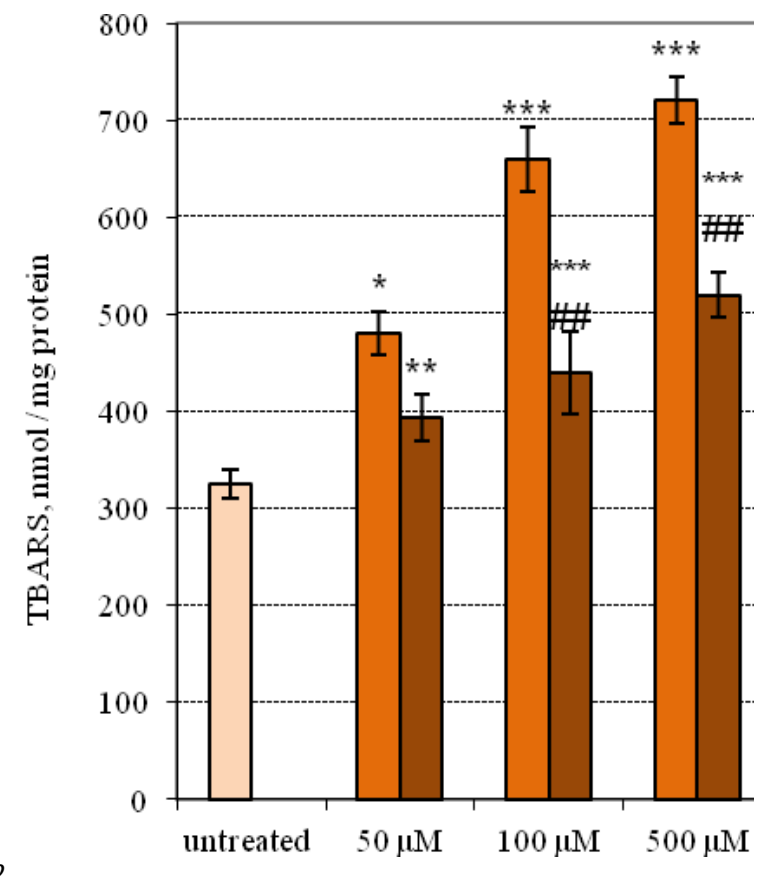

Fig. 1. Effect of superoxide anion-generating system $\mathrm{Fe}^{3+}$ /ascorbate $(\square)$ and $\mathrm{H}_{2} \mathrm{O}_{2}(\square)$ on the TBARS level in spermatozoa of normozoospermic (a) and asthenozoospermic (b) men. Sperm cells were incubated for $5 \mathrm{~min}$ at $37^{\circ} \mathrm{C}$ as described in "Material and Methods". Data are presented as $\mathrm{x} \pm$ SE. * $-\mathrm{P}<0.05$; *** $-\mathrm{P}<0.001$ compared to untreated cells; \#- $\mathrm{P}<0.05$; \#\#- $\mathrm{P}<0.01$ compared to cells treated with $\mathrm{H}_{2} \mathrm{O}_{2}$. GSTs enzyme activity in response to induced oxidative stress
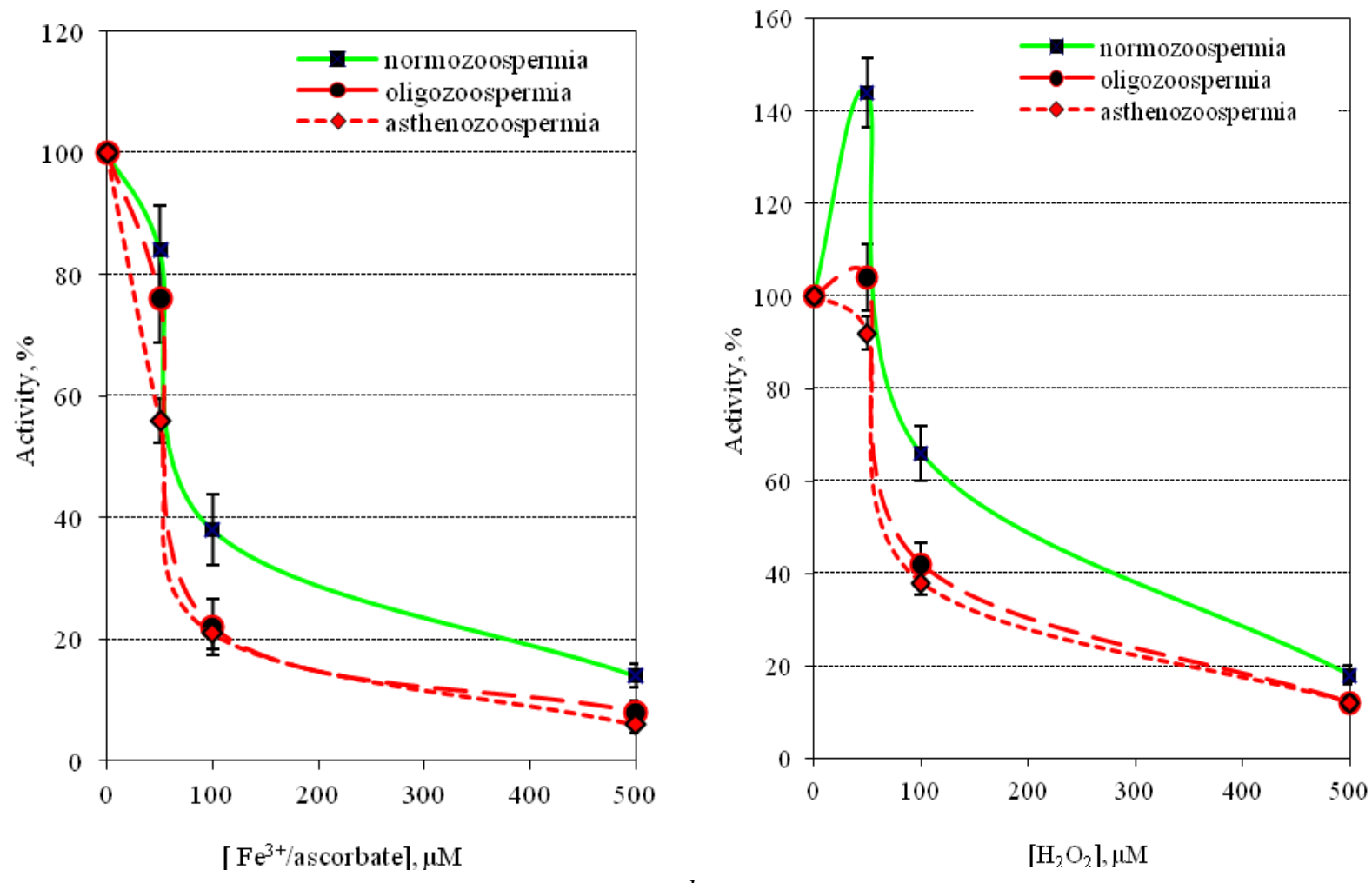

$b$

Fig. 2. Effect of superoxide anion-generating system $\mathrm{Fe}^{3+}$ /ascorbate $(a)$ and $\mathrm{H}_{2} \mathrm{O}_{2}(b)$ on the GSTs activity of spermatozoa of fertile and infertile men. Sperm cells were incubated for $5 \mathrm{~min}$ at $37^{\circ} \mathrm{C}$ as described in "Material and Methods". Data are expressed as the percent residual GSTs activity considering $100 \%$ the activity assayed in the absence of ROS. Data are presented as $\mathrm{x} \pm \mathrm{SE}$ 


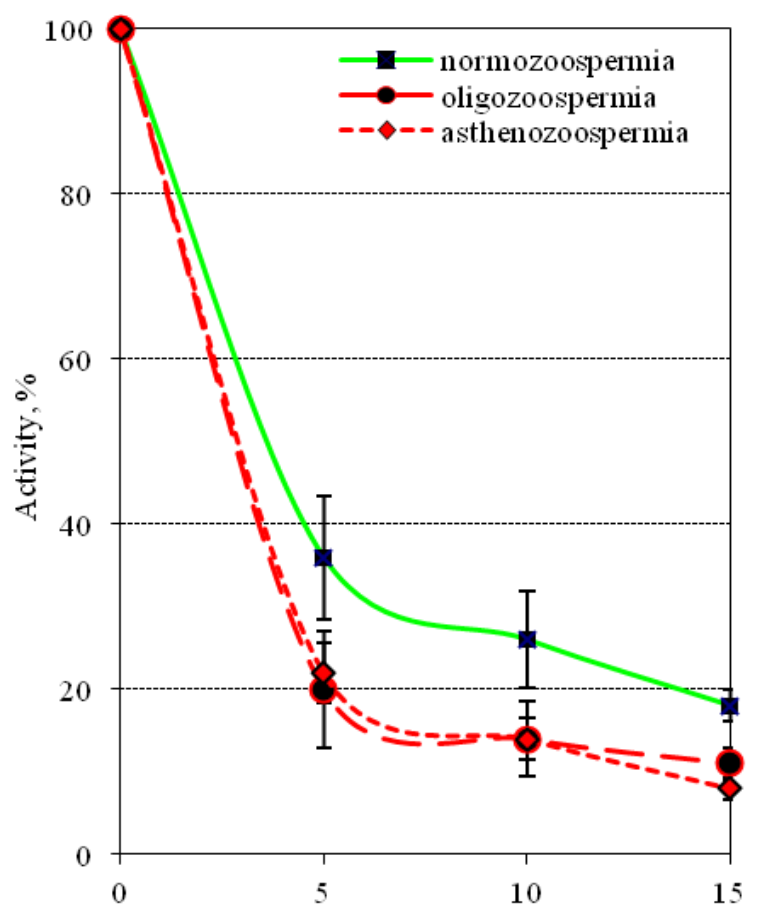

[Incubation time], min

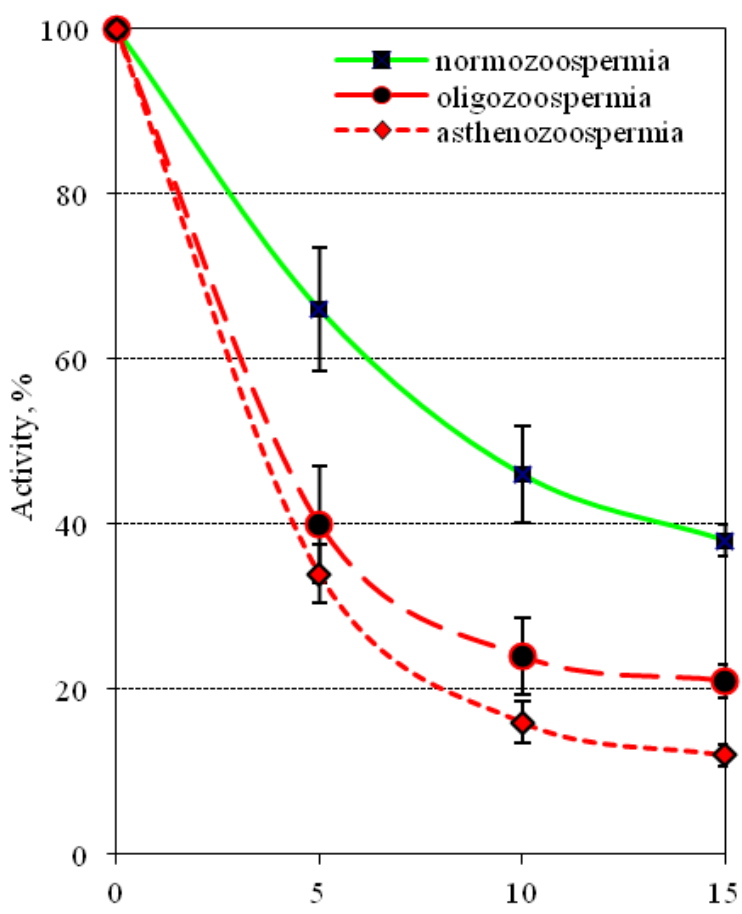

[Incubation time], min $a$

$b$

Fig. 3. Time course of GSTs inhibition by anion-generating system $\mathrm{Fe}^{3+} /$ ascorbate $(a)$ and $\mathrm{H}_{2} \mathrm{O}_{2}(b)$ in spermatozoa of fertile and infertile men. Sperm cells were incubated with $100 \mu \mathrm{M} \mathrm{Fe}^{3+} / 1 \mathrm{mM}$ ascorbate or $\mathrm{H}_{2} \mathrm{O}_{2}$ as described in "Material and Methods". Data are expressed as the percent residual GSTs activity considering $100 \%$ the activity assayed in the absence of ROS. Data are presented as $\mathrm{x} \pm \mathrm{SE}$

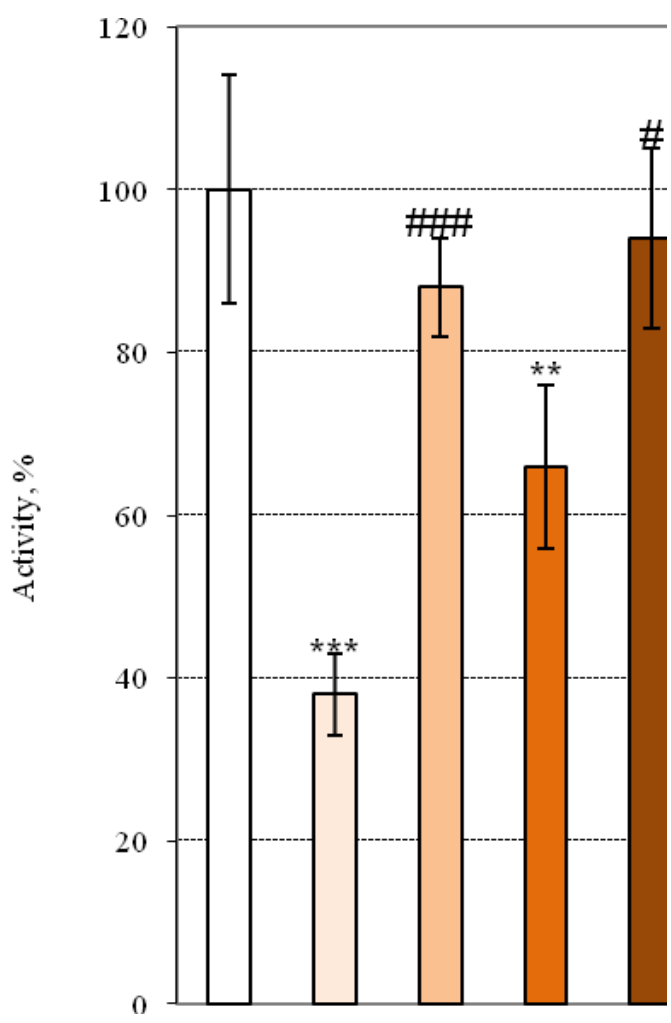

$a$

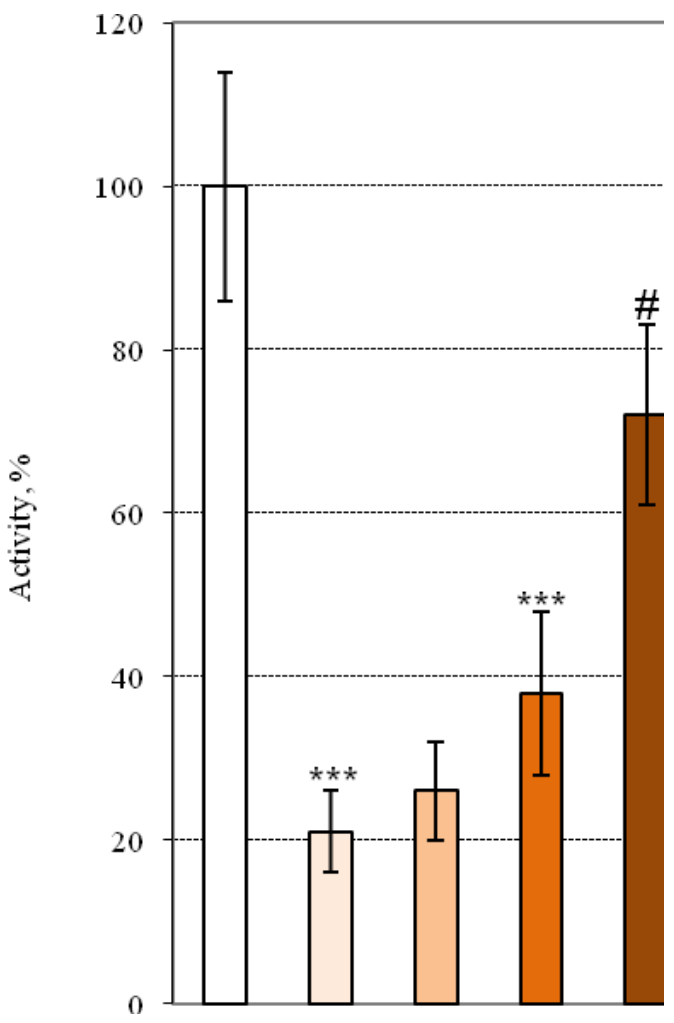

$b$

Fig. 4. Effect of superoxide anion-generating system $\mathrm{Fe}^{3+}$ /ascorbate, $\mathrm{H}_{2} \mathrm{O}_{2}$ and $\mathrm{GSH}$ on the GSTs activity of spermatozoa of normozoospermic $(a)$ and asthenozoospermic $(b)$ men. Data are expressed as the percent residual GSTs activity considering $100 \%$ the activity assayed in the absence of ROS. $\square$ - control, $\square-\mathrm{Fe}^{3+}$ /ascorbate, $\square-\mathrm{Fe}^{3+}$ /ascorbate $+\mathrm{GSH}, \square-\mathrm{H}_{2} \mathrm{O}_{2}, \square-\mathrm{H}_{2} \mathrm{O}_{2}+\mathrm{GSH}$. Data are presented as $\mathrm{x} \pm \mathrm{SE}$. ** $-\mathrm{P}<0.01$; *** $-\mathrm{P}<0.001$ compared to untreated cells; \#- $\mathrm{P}<0.05$; \#\# $-\mathrm{P}<0.01$ compared to cells treated with $\mathrm{Fe}^{3+} /$ ascorbate or $\mathrm{H}_{2} \mathrm{O}_{2}$ without $\mathrm{GSH}$ 
Here in the present study an increase in the TBARS levels was found in spermatozoa treated with increasing concentration of $\mathrm{Fe}^{3+} / \mathrm{as}-$ corbate or $\mathrm{H}_{2} \mathrm{O}_{2}$. Peroxidation of membrane lipids is an indicator of oxidative stress experienced by the cells. It is known that the malondialdehyde level (evaluated as TBARS) reflects the amount of lipid damage due to ROS attacks (Monaghan et al., 2009). Since ROS are able to oxidize lipids in spermal membranes, the lipid peroxidation status of the sperm was checked with TBARS formation, which are the end products of lipid peroxidation.

GSTs are currently investigated conjugation enzymes. The physiological role of GSTs has been studied in several papers. They serve as bifunctional molecules in a transcriptionally inactive cell whose requirement for cellular defense and economy of molecules that it can carry is greater than that of any somatic cell type (Hemachand et al., 2002). GSTs play an important role in sperm physiology. Specifically, sperm GSTs are important in antioxidant protection in spermatozoa against oxidative stress since infertile men with a null genotype for GST-Mu1 have spermatozoa with significant oxidative damage (Aydemir et al., 2007). It was shown that GSTs polymorphisms were not associated with sperm quality in humans, however only GSTT1 was associated with decreased sperm concentration (Olshan et al., 2010). Also it was shown that GST M1 null genotype predisposes sperm to increased oxidative damage in patients with varicocele (Chen et al., 2002; Tang et al., 2012).

Here in the present study, dose dependent decrease in the GSTs activity was found in spermatozoa treated with increasing concentration of $\mathrm{H}_{2} \mathrm{O}_{2}$ and $\mathrm{Fe}^{3+}$ /ascorbate. However, in normozoospermic samples low concentrations of $\mathrm{H}_{2} \mathrm{O}_{2}(50 \mu \mathrm{M})$ induce activation of sperm GSTs activity in comparison to untreated cells, which can be explainned as a defence response to oxidative stress. The decrease of GSTs activity in higher ROS concentrations indicates the depletion of compensatory mechanisms in normo- and pathospermic samples. Preincubation of spermatozoa with GSH completely prevented the ROS-induced inhibition on GSTs only in normozoospermic samples. This suggests that GSH partially protects the $\mathrm{Na}^{+}, \mathrm{K}^{+}$-ATPase from inhibition under experimental oxidative stress.

There are some limitations to the present study. First, our control group (normozoospermic men with proven fertility) and pathospermic patients contained a highly heterogeneous population, with large variations in spermogram parameters and infertility histories. Second, it is therefore essential to validate our findings with greater sample sizes and to determine the disease specificity (secretory or excretory infertility, varicocele or others) by comparing spermogram parameters. Nevertheless, the present study extends previous work and provides further evidence of decreased GSTs activity in pathospermic samples.

The present study clearly demonstrates the functional role of sperm GSTs in protection against oxidative stress and provides an insight into possible defects in the functioning of the GSTs in sperm that may lead to impaired male fertility. The obtained results argue for a biological role of sperm GSTs in susceptibility of spermatozoa to oxidative damage and maintaining sperm antioxidant status.

\section{Conclusions}

The results of our study showed higher oxygen-free radical production, evidenced by increased TBARS level in spermatozoa obtainned from infertile men than normozoospermic men. The inhibitory effect of the radical (superoxide anion-generating system $\mathrm{Fe}^{3+}$ /ascorbate) species on sperm GSTs activity and lipid peroxidation products in spermatozoa of fertile and infertile men were more expressed compared to non-radical $\left(\mathrm{H}_{2} \mathrm{O}\right)$ species. Our results indicate that estimation of sperm GSTs enzyme assays can be used as a bioindicator for impaired male fertility.

The publication contains the results of studies conducted under the President of Ukraine's grant for competitive projects (project No $\Phi 63 / 97-2016$ from 10.08.2016 "Molecular biological regulatory mechanisms of disturbance of fertilizing ability of spermatozoa and the development of new immunobiochemical diagnostic methods of fertility in men" of the State Fund for Fundamental Research (The President's Order No 97/2016-pп, April 13, 2016).

\section{References}

Aitken, R. J., Jones, K. T., \& Robertson, S. A. (2012). Reactive oxygen species and sperm function - in sickness and in health. Journal of Andrology, 33(6), 1096-1106.

Aydemir, B., Onaran, I., Kiziler, A. R., Alici, B., \& Akyolcu, M. C. (2007). Increased oxidative damage of sperm and seminal plasma in men with idiopathic infertility is higher in patients with glutathione S-transferase Mu-1 null genotype. Asian Journal of Andrology, 9(1), 108-115.

Ball, B. A., Vo, A. T., \& Baumber, J. (2001). Generation of reactive oxygen species by equine spermatozoa. American Journal of Veterinary Research, 62(4), 508-515.

Buzadzic, B., Vucetic, M., Jankovic, A., Stancic, A., Korac, A., Korac, B., \& Otasevic, V. (2015). New insights into male (in)fertility: The importance of NO. Brazilian Journal of Pharmacology, 172(6), 1455-1467.

Chen, S. S., Chang, L. S., Chen, H. W., \& Wei, Y. H. (2002). Polymorphisms of glutathione S-transferase M1 and male infertility in Taiwanese patients with varicocele. Human Reproduction, 17, 718-725.

Cheng, H., Tchaikovskaya, T., Tu, Y., Chapman, J., Qian, B., Ching, W., Tien, M., Rowe, J. D., Patskovsky, Y. V., Listowsky, I., \& Tu, C. D. (2001). Ra glutathione S-transferase M4-4: An isoenzymes with unique structural features including a redox-reactive cysteine-115 residue that forms mixed disulphides with glutathione. Biochemical Journal, 356, 403-441.

Esteves, S. C., \& Agarwal, A. (2011). Novel concepts in male infertility. International Brazilian Journal of Urology, 37, 5-715.

Esteves, S. C., \& Chan, P. (2015). A systematic review of recent clinical practice guidelines and best practice statements for the evaluation of the infertile male. International Urology and Nephrology, 47, 1441-1456.

Fafula, R. V., Meskalo, O. I., Lychkovskyy, E. I., \& Vorobets, Z. (2017). Efekty gidrogen peroksydu na osnovni kinetychni parametry gidrolizu ATR ubai'nchutlyvoju $\mathrm{Ca}^{2+}, \mathrm{Mg}^{2+}$-ATR-azoju spermatozoi'div infertyl'nyh cholovikiv [Effect of hydrogen peroxide on the main kinetic parameters of ATP hydrolysis by $\mathrm{Ca}^{2+}, \mathrm{Mg}^{2+}$-ATP-ase in spermatozoa of infertile men]. Experimental and Clinical Physiology and Biochemistry, 80(4), 46-51 (in Ukrainian).

Fafula, R. V., Onufrovych, O. K., \& Iefremova, U. P. (2017). Intensyvnist' procesiv lipoperoksydacii' u spermatozoi'dah cholovikiv iz porushennjam [Intensity of processes of lipid peroxidation in sperm of men with impaired fertility ]. Bulletin of Problems Biology and Medicine, 135(1), 199-204 (in Ukrainian).

Farombi, E. O., Adelowo, O. A., \& Ajimoko, Y. R. (2007). Biomarkers of oxidative stress and heavy metal levels as indicators of environmental pollution in African cat fish (Clarias gariepinus) from Nigeria Ogun River. International Journal of Environmental Research and Public Health, 4(2), 158-165.

Garrido, N., Meseguer, M., Simon, C., Pellicer, A., \& Remohi, J. (2004). Prooxidative and antioxidative imbalance in human semen and its relation with male fertility. Asian Journal of Andrology, 6, 59-65.

Halliwell, B. (2007). Biochemistry of oxidative stress. Biochemical Society Transactions, 35(5), 1147-1150

Halliwell, B., \& Gutteridge, J. (2007). Free radicals in biology and medicine. Oxford University Press, Oxford.

Hayes, J. D., Flanagan, J. U., \& Jowsey, I. R. (2005) Glutathione transferases. Annual review of pharmacology and toxicology, 45, 51-88.

Hemachand, T., Gopalakrishnan, B., Salunke, D. M., Totey, S. M., \& Shaha, C. (2002). Sperm plasma-membrane-associated glutathione S-transferases as gamete recognition molecules. Journal of Cell Science, 115(10), 2053-2065.

Hesham, N., Moemen, L. A., \& Abu Elela, M. H. (2008). Studing the levels of malondialdehyde and antioxidant parameters in normal and abnormal human seminal plasma. Australian Journal Basic and Applied Sciences, 2(3), 773-778

Joffe, M. (2010). What has happened to human fertility? Human Reproduction, 25, 295-307.

Letelier, M. E., Molina-Berríos, A., Cortés-Troncoso, J., Jara-Sandoval, J. A., Müller, A., \& Aracena-Parks, P. (2010). Comparative effects of superoxide anion and hydrogen peroxide on microsomal and cytosolic glutathione S-transferase activities of rat liver. Biological Trace Element Research, 134(2), 203-211.

Monaghan, P., Metcalfe, N. B., \& Torres, R. (2009). Oxidative stress as a mediator of life history trade-offs: Mechanisms, measurements and interpretation. Ecology Letters, 12, 75-92.

Nissar, S., Sameer, A. S., Rasool, R., Chowdri, N. A., \& Rashid, F. (2017) Glutathione S transferases: Biochemistry, polymorphism and role in colorectal carcinogenesis. Journal of Carcinogenesis and Mutagenesis, 8, 2.

Olshan, A. F., Luben, T. J., \& Hanley, N. M. (2010). Preliminary examination of polymorphisms of GSTM1, GSTT1, and GSTZ1 in relation to semen quality. Mutation Research - Fundamental and Molecular Mechanisms of Mutagenesis, 688(1-2), 41-46. 
Onaran, I., Guven, G., Ozaydin, A., \& Ulutin, T. (2001). The influence of GSTM1 null genotype on susceptibility to in vitro oxidative stress. Toxicology, 157(3), 195-205.

Sahoo, D. K. (2011). Effects of thyroid hormone on testicular functions and antioxidant defence status. Biochemistry: An Indian Journal, 5(6), 337-334.

Said, T. M., Agarwal, A., Sharma, R. K., Thomas, A. J., \& Sikka, S. C. (2005). Impact of sperm morphology on DNA damage caused by oxidative stress induced by beta-nicotinamide adenine dinucleotide phosphate. Fertility and Sterility, 83, 95-103.

Sakkas, D., Seli, E., Bizzaro, D., Tarozzi, N., \& Manicardi, G. C. (2003). Abnormal spermatozoa in the ejaculate: Abortive apoptosis and faulty nuclear remodelling during spermatogenesis. Reproductive Biomedicine Online, $7,428-432$.

Storey, B. T. (2008). Mammalian sperm metabolism: Oxygen and sugar, friend and foe. International Journal of Developmental Biology, 52(5-6), 427-437.
Tang, K., Xue, W., Xing, Y., Xu, S., Wu, Q., Liu, R., Wang, X., \& Xing, J. (2012). Genetic polymorphisms of glutathione S-transferase $M_{1}, T_{1}$, and $\mathrm{P}_{1}$, and the assessment of oxidative damage in infertile men with varicoceles from northwestern China. Journal Andrology, 33(2), 257-263.

Timirbulatov, R., \& Seleznev, E. (1981). Metody povyshenija intensivnosti svobodno-zadikal'nogo okislenija lipidosoderzhashhih komponentov krovi i ego diagnosticheskoe znachenie [Method of increasing intensity of freeradical oxidization of lipid components of blood and its diagnostic value]. Laboratory Business, 4, 209-211 (in Russian).

Vorobets, D., \& Kocheshkova, N. (2008). Neplidnist' ta erektil'na disfunkcija cholovikiv: Biohimichni ta klinichni aspekty [Infertility and erectile dysfunction men: Biochemical and clinical aspects]. Ukrmedknyha, Ternopil (in Ukrainian). 